\title{
The Effect of Democratically Determined (In)equality on Cooperative Behavior
}

\author{
Thomas Schlösser • Tim Steiniger • Daniel Ehlebracht • \\ Detlef Fetchenhauer
}

Published online: 9 April 2020

(C) The Author(s) 2020

\begin{abstract}
We investigated the relationship between democratically determined economic inequality and cooperation in a two-stage experimental design. Although the relationship between inequality and cooperation has been studied extensively, experimental results in this area are contradictory and find inequality to have either a positive, negative, or no effect on cooperation. Our participants were randomly assigned to one of three societal classes (upper class, middle class, lower class) in a simulated small-scale society, and they subsequently voted to implement a societal system in which wealth was distributed either relatively equally or relatively unequally. We found lower levels of cooperation (measured as the invested amount in a public-good game) among societies that previously opted for the unequal distribution, but did not observe a general effect of a participant's personal vote on cooperative behavior. Instead, middle-class and lower-class participants in unequal societies cooperated less than their counterparts in the equal societies, causing the observed differences on the societal level. These findings suggest that democratically induced policies that ultimately lead to greater equality of wealth are potentially able to have positive consequences on the readiness to cooperate on the production of public goods.
\end{abstract}

\footnotetext{
T. Schlösser $(\varangle) \cdot$ D. Ehlebracht $\cdot$ D. Fetchenhauer Institut für Soziologie und Sozialpsychologie, Universität zu Köln Universitätsstr. 24, 50931 Cologne, Germany

E-Mail: t.schloesser@uni-koeln.de

D. Ehlebracht

E-Mail: daniel.ehlebracht@uni-koeln.de

D. Fetchenhauer

E-Mail: detlef.fetchenhauer@uni-koeln.de

T. Steiniger

Cologne, Germany
} 
Keywords Inequality $\cdot$ Public-good game $\cdot$ Cooperation $\cdot$ Voting $\cdot$ Democratic decisions

\section{Die Auswirkung demokratisch gewählter (Un)gleichheit auf kooperatives Verhalten}

Zusammenfassung Diese Studie untersucht den Zusammenhang zwischen demokratisch bestimmter wirtschaftlicher Ungleichheit und Kooperation in einem zweistufigen Versuchsdesign. Obwohl der Zusammenhang zwischen Ungleichheit und Kooperation bereits ausführlich untersucht wurde, sind die experimentellen Ergebnisse in diesem Bereich widersprüchlich. Einige Studien finden einen positiven Effekt zwischen Ungleichheit und Kooperation, andere einen negativen Effekt, und einige Studien finden überhaupt keinen Zusammenhang zwischen Ungleichheit und Kooperation. Unsere Teilnehmerinnen und Teilnehmer einer experimentellen Laborstudie wurden zufällig einer von drei Gesellschaftsklassen (Oberschicht, Mittelschicht, Unterschicht) in einer simulierten Kleinstgesellschaft zugeordnet und stimmten anschließend demokratisch für die Umsetzung eines Gesellschaftssystems, in dem der Wohlstand entweder relativ gleichmäßig oder relativ ungleich verteilt wurde. Die Ergebnisse dieser Studie zeigen ein geringeres Maß an Kooperation in den Gesellschaften, welche sich zuvor für die ungleiche Verteilung entschieden haben. Ein allgemeiner Effekt der persönlichen Wahlentscheidung der Versuchspersonen für ein bestimmtes Verteilungssystem auf das kooperative Verhalten ließ sich jedoch nicht beobachten. Insbesondere Teilnehmerinnen und Teilnehmer der Mittelschicht und der Unterschicht in ungleichen Gesellschaften kooperierten weniger als die Teilnehmer der gleichen Klassen in gleicheren Gesellschaften, was zu den beobachteten Unterschieden auf der Aggregatebene führte. Diese Ergebnisse deuten potenziell an, dass demokratisch induzierte politische Maßnahmen, welche zu mehr Gleichverteilung von Wohlstand führen, die Bereitschaft zur Kooperation hinsichtlich der Produktion von öffentlichen Gütern fördern kann.

Schlüsselwörter Ungleichheit · Öffentliches-Gut-Spiel · Kooperation · Wahlverhalten · Demokratische Entscheidungen

\section{Introduction}

In all societies, some citizens are richer than others are. However, countries highly differ in their degree of inequality. It has been shown that inequality does lower citizens' willingness to voluntarily participate in contributing to collective goods, but this might be due to the perceived unfairness of a highly unequal distribution of income. In recent years, there have been controversial discussions about the possible association between wealth and income disparities and various undesirable societal phenomena (e.g., Saunders 2010; Wilkinson and Pickett 2009), among them low levels of trust and cooperation, which have been argued to ultimately hamper economic growth (Knack and Keefer 1997; Zak and Knack 2001). Although the relationship between inequality and cooperation has been studied extensively, ex- 
perimental results in this area are, at first glance, contradictory and find inequality to have either a positive (e.g., Chan et al. 1996), negative (e.g., Anderson et al. 2008; Haile et al. 2008; van Dijk et al. 2002), or no effect on cooperation (e.g., Chan et al. 1999; Reuben and Riedl 2013; Sadrieh and Verbon 2006). At second glance, it seems to be the case that, in recent years, cumulative evidence mostly stemming from behavioral economic research suggests that inequality is negatively linked to cooperation (see also, e.g., Paetzel and Traub 2017). Recent studies might partly explain these conflicting findings by showing that the origin of inequality is crucial when determining its behavioral consequences (Greiner et al. 2012; Haile et al. 2008). Therefore, we aimed to investigate the effect of simulated societal inequality that results from a democratic process on cooperative behavior in an experimental design. To assess participants' level of cooperativeness, our experiment incorporated a public-good game. In contrast to various previous studies (Buckley and Croson 2006; Isaac and Walker 1988), inequality is not induced exogenously. Instead, it is induced by employing a behavioral paradigm called the welfare-state game (Biniossek and Fetchenhauer 2007; Lotz and Fetchenhauer 2012; Schlösser et al. 2018). In the welfare-state game, participants are assigned to fictive societal classes (the upper class, middle class, or lower class) and democratically decide whether payoffs are distributed comparatively equally or unequally. Hence, in a first phase, participants democratically determine their society's level of inequality, while being aware of their position in a society's social hierarchy (analogous to "straight mode" in Bolton and Ockenfels 2006). In a second phase, participants take part in a subsequent cooperation task, namely a public-good game. With the help of this design, we transferred the functional principle of a democratic welfare state to an experimental environment and investigated its consequences for subsequent cooperative behavior. To the best of our knowledge, we are the first to do so. Based on theoretical and empirical evidence (Lotz and Fetchenhauer 2012; Norton and Ariely 2011; Schlösser et al. 2018), we predicted that most of these fictive societies would opt for the more equal wealth distribution. In line with this prediction, our results reveal an overall preference for a society in which wealth is distributed relatively equally, with large proportions of upper-class and middle-class participants voting in favor of a low degree of inequality, even though that decision will result in financial losses to them. With regard to the main dependent variable (i.e., cooperative behavior), we show that inequality undermines cooperation, even if it is democratically determined. Contributions to the public good are larger among groups of participants who implemented an equal society. Furthermore, we found no evidence that this result is based on mechanisms of self-selection, similarity, or risk or inequality aversion. Comparing the participants assigned to different societal classes, we found that an unequal welfare distribution evokes lower levels of cooperation, especially among middle-class and lower-class participants, which suggests that the mechanism behind this relationship is potentially driven by motivated reasoning. 


\section{Previous Findings}

\subsection{Inequality and Cooperation}

Previous experimental studies that target the association between inequality and cooperation suggest the existence of a complex relationship. While some studies found positive effects of inequality on cooperative behavior (e.g., Chan et al. 1996), others found negative effects (e.g., Anderson et al. 2008; Haile et al. 2008; van Dijk et al. 2002) or no effect at all (e.g., Chan et al. 1999; Reuben and Riedl 2013; Sadrieh and Verbon 2006). These varying results might be partly explained by recent research suggesting that the origin of inequality is especially important when determining its eventual effect on cooperation (Greiner et al. 2012; Haile et al. 2008).

By conducting an experiment based on a repeated trust game, Greiner et al. (2012) found different behavioral patterns for exogenously and endogenously induced inequality: The authors report that trust is initially low, though relatively stable over 20 rounds, in the condition where inequality was induced exogenously. However, when inequality was caused by the decisions of the participants (endogenous origin), initial trust rates were high but decreased over time to a low level. This result was explained by the different informational value of endogenous and exogenous inequality: Endogenous inequality was necessarily a consequence of previous untrustworthy behavior because all participants initially received the same endowment and could gain higher earnings than others only by exploiting others' trustfulness. By contrast, exogenous inequality did not allow for the same inferences because the participants' initial endowments differed, which, after a few rounds, made it impossible to tell whether a participant's wealth resulted from a high initial endowment or untrustworthy behavior. These results suggest that participants use the level of endogenous inequality to make inferences about their counterparts' previous behavior. Because trust is closely related to cooperation and has even previously been called "the expectation of cooperation" (Pruitt and Kimmel 1977, p. 375), it can be assumed that decreasing levels of trust go hand in hand with diminished cooperation in a public-good game. However, because in a public-good game a certain amount of trust is essential for cooperation, inferences about cooperative behavior might be deduced from its results as well.

Indeed, in a related experiment Haile et al. (2008) found that endogenous inequality (but not exogenously induced inequality) affects cooperation in a version of the public-good game. In their experiment, inequality either was implemented randomly or resulted from a choice of a dictator who personally benefited from higher inequality. The findings showed that inequality influenced public-good contributions only if it resulted from the choice of the dictator. In this case, higher inequality decreased overall contributions to the public good. Taken together, both studies indicate that the source of inequality is crucial for determining its consequences and suggest that endogenous inequality hampers cooperation.

Given these findings, we find it surprising that a common practice of policy-making has been mostly neglected in experimental research, namely, majority choices. Previous research investigated the impact of democratically chosen institutions, such 
as sanctioning and rewarding mechanisms, on cooperation (see Balafoutas et al. 2013; Dal Bó et al. 2010; Kosfeld et al. 2009; Putterman et al. 2011; Sutter et al. 2010; Walker et al. 2000). Economic choice models that formalize motives of inequality aversion and fairness were influential in predicting choice in social dilemmas, such as cooperation tasks (e.g., Bolton and Ockenfels 2000; Fehr and Schmidt 1999). However, to the best of our knowledge, the effect of a democratically chosen wealth distribution on subsequent cooperative behavior has yet to be explored.

\subsection{Democratic Determination of Inequality}

In democratic welfare states, policies of income redistribution are ultimately the result of majority decisions. For instance, voters empower parties that promote a flat or a progressive taxation system and thus select different degrees of redistribution, consequently leading to different degrees of inequality. Hence, a society's level of inequality can partly be seen as the result of a democratic vote.

One factor that people are likely to consider when they vote on the level of inequality is their own position in a society's social hierarchy. From a rational actor's perspective, it might be argued that citizens should always favor distributions that financially benefit their own position (class). Hence, facing the decision between a society with a low degree of inequality and a society with a high degree of inequality, those who financially benefit from inequality should prefer the society with a more unequal wealth distribution. Vice versa, those who benefit from less inequality should prefer a society with a more equal wealth distribution.

However, numerous empirical findings have shown that a notable proportion of people generally prefer comparatively equal wealth and income distributions over more unequal ones (Dawes et al. 2007; Lotz and Fetchenhauer 2012; Norton and Ariely 2011). Recently, Norton and Ariely (2011) asked participants of a representative sample of U.S. citizens to design a society in which wealth is ideally distributed. The results indicated that participants of all regarded demographic groups preferred considerably more equal wealth distributions than those observed in reality: $92 \%$ of participants preferred a society with a "Swedish" wealth distribution over a society with an "American" wealth distribution. Experimental research has shown that this preference for equally distributed wealth persists even if more equality yields personal financial losses and less total societal wealth (Lotz and Fetchenhauer 2012; Schlösser et al. 2018).

\subsection{Behavioral Predictions}

Based on the literature reviewed, we expected that our participants would generally prefer a more equal wealth distribution. However, the share of participants opting for more equality should differ depending on their given position in the social hierarchy. In our experiment, participants were randomly assigned to a lower, middle, or upper class in three-person "micro societies." The wealth distributions were designed in such a way that upper-class and middle-class participants had a financial incentive to opt for an unequal society, whereas lower-class participants had a financial incentive 
to opt for an equal society. Hence, the largest proportion of equality voters should be found among lower-class participants.

We further assumed that societies that opt for a greater degree of income inequality by their majority vote show less subsequent cooperative behavior. We will discuss to what degree this effect is based on different mechanisms, such as the selfselection of cooperative participants into equal societies, similarity considerations, risk considerations, inequality aversion, and motivated reasoning.

First, a mechanism based on self-selection assumes that participants who vote for equality are generally more prosocial and, in turn, more cooperative than their counterparts (e.g., Bergh and Bjørnskov 2014). If this were true, one would observe a higher level of cooperation among those participants who vote for equality, irrespective of the degree of inequality that is implemented by the majority vote in their society.

Second, a mechanism based on similarity considerations argues that people are prone to cooperate with those who are more similar to themselves. It has been suggested that similarity is a crucial component in the evolution of cooperation (Riolo et al. 2001), and previous research has found that perceived similarity motivates cooperation in social dilemmas (Fischer 2009). In the same vein, cooperation has been found to increase among interaction partners who perceive that they share attitudes (Fischer 2009). In the context of democratic decision-making, this finding suggests that people might cooperate more readily and more often if most people in their society share their attitudes. In contrast, high wealth inequality might emphasize dissimilarities and consequently discourage cooperation. Hence, a similarity-based mechanism suggests that, in a democratic system, wealth equality or inequality per se should not necessarily lead to higher or lower cooperation. Instead, participants who voted in accordance with the majority vote (i.e., their preference regarding the appropriate degree of inequality is similar to the majority's attitude) should act especially cooperatively irrespective of the eventually determined level of inequality, due to the fact that they perceive similarity between their own and the majority's preferences or attitudes.

Third, a mechanism based on risk considerations argues that the societal level of inequality acts as a proxy for participants' previous behavior (Greiner et al. 2012). This mechanism implies that the democratic vote for more inequality might signal self-interested behavior and thereby increase the expected probability ${ }^{1}$ of being exploited, which in turn reduces trust and cooperation. Therefore, this mechanism predicts a decrease in the willingness to cooperate among all members of an unequal society, as the majority of them voted for inequality and therefore in most cases (upper and middle class) in favor of their own economic welfare. Consequently, the general risk of exploitation might be perceived higher in unequal compared with equal societies.

\footnotetext{
1 In the context of this work, the term risk is used in the sense of a subjective probability derived from and attached to the behavior of the other group members-which equals an expectation regarding others' behavior. This resembles the understanding of risk in expected utility theories of choice under risk and uncertainty (e.g., Chaplin and Leahy 2001; Kahneman and Tversky 1979; Savage 1954; von Neumann and Morgenstern 1944).
} 
Fourth, a mechanism based on inequality aversion suggests that inequality decreases cooperation in societies as a by-product of efforts to distribute wealth more equally (Bolton and Ockenfels 2000; Fehr and Schmidt 1999). As inequality-averse individuals are concerned not only about their own wealth but also about the general distribution of wealth within their society, they aim to redistribute resources if wealth disparities surpass a certain threshold. One way to partly reallocate the society's wealth and reduce inequality is the provision of public goods financed by the upper class without the contributions and, in turn, the cooperation of the lower classes. Hence, low-income inequality-averse individuals might regard wealthy individuals as responsible for the provision of public goods that benefit the society as a whole. Likewise, wealthy inequality-averse individuals might actually be willing to cede a part of their wealth to reduce wealth disparities. Thus, a mechanism based on inequality aversion simultaneously predicts an increase in cooperation on the part of the wealthy and a decrease in cooperation on the part of the poor. Because in the present experiment cooperation is measured as contributions to the public good, this mechanism suggests that in micro societies that voted for inequality, the upper-class and middle-class participants who benefited monetarily from the implementation of the unequal system would be more willing, whereas the disadvantaged lower-class participants would be less willing to contribute to the public good.

Finally, a mechanism based on motivated reasoning suggests that people generally prefer to act in their own self-interest as long as they are able to justify their behavior. This justification has to surpass a certain threshold of plausibility, but people's motivation to arrive at their desired conclusion may cause them to selectively search their memory for beliefs and rules that may promote rather than hinder their justification efforts (Kunda 1990). Consequently, inequality would decrease cooperation if it is in the self-interest of a majority not to cooperate and if inequality delivers a plausible justification to argue that this behavior is appropriate.

In the present experiment, high inequality benefits upper-class participants the most and middle-class participants to some degree, and lower-class participants suffer from its implementation. Hence, after inequality is implemented and participants are asked to cooperatively contribute to the public good, lower-class participants might be motivated to reason that it is only fair if the previously benefiting middleclass and upper-class participants provide the public good on their own. As Rawls (1971) hypothesized, those who suffer from societal inequality show "excusable envy" that he explained in the following way, which can easily be understood as one form of motivating reasoning: "A person's lesser position as measured by the index of objective primary goods may be so great as to wound his self-respect; and given his situation, we may sympathize with his sense of loss. Indeed, we can resent being made envious, for society may permit such large disparities in these goods that under existing social conditions these differences cannot help but cause a loss of selfesteem. For those suffering this hurt, envious feelings are not irrational" (p. 534). Along these lines, the "excusable envy" lower-class members would have good reasons not to cooperate with higher-class participants, as they would be reluctant to contribute to any increase in the wealth of the latter.

However, middle-class participants might not want to contribute either and thus may be motivated to neglect the fact that they benefited from inequality. Instead, 
they may compare themselves with upper-class participants and reason that the upper class benefited the most and should thus provide the public good on its own. By contrast, upper-class participants may find no sufficiently plausible reason why middle-class or lower-class participants should contribute more to the public good than they do, but they also do not want to play the role of their paymasters. In line with our argumentation, recent psychological research has shown that feeling subjectively higher in social class is positively connected to blindness for inequality and goes hand in hand with justification of the prevailing economic system and of holding beliefs that oppose wealth redistribution (Rodriguez-Bailon et al. 2017). Thus, along the lines of motivated reasoning, inequality should not influence the cooperativeness of upper-class participants; however, cooperation among middleclass and lower-class participants should decrease, causing an overall decrease in cooperative behavior under conditions of high inequality.

The conducted experiment is most closely related to the study by Haile et al. (2008). We aimed to examine the effect of inequality in experimental micro societies on cooperation. However, our experiment still differs in crucial ways. First, our experiment employed a democratic vote to determine the degree of inequality instead of a dictatorial decision and, in turn, provides valuable insights into the effect of economic inequality on cooperative behavior. Second, we randomly assigned our participants to a fictional upper, middle, or lower class, which allowed us to investigate whether the effect of inequality on cooperation does or does not depend on an individual's societal status. Third, we did not alter the size of our participants' endowments and thus did not alter their behavioral options in the public-good game (Anderson et al. 2006).

\section{Method}

Participants were recruited on the campus of a large German university; 342 persons agreed to participate in a study about decision-making. All the participants were told that the experiment included decisions about real monetary payoffs, yet they were not promised any specific payment amount. Seventy participants had to be excluded from the analysis for reasons such as incorrect answers to control questions (in sum, $n=55,3$ with respect to the voting procedure and 52 with respect to the publicgood game; for further explanation, see end of procedure section), missing values in one of our focal variables $(n=4)$, or experimenter mistakes $(n=11)$, leaving an adjusted sample of 272 participants, comprising $162(60 \%)$ women and $110(40 \%)$ men aged $18-43$ years $($ mean $=22.77$, standard deviation $[S D]=3.77)$. The excluded participants did not differ significantly from the participants who stayed in the analysis in any of the regarded variables (i.e., voting and cooperative behavior). On average, participants earned $€ 8.54$ in approximately $30 \mathrm{~min}$. Sample size was determined by resource limitations, as the behavioral measures were monetarily incentivized. For this reason, from the beginning we aimed for approximately 100 participants in each of the three possible societal positions; recruiting stopped as this goal was reached by the research assistants. Expectations about effect sizes were not based on prior research as there were no applicable examples in the literature. 
All procedures performed in this study were in accordance with the ethical standards of the ethics committee of the national psychological society and with the 1964 Helsinki Declaration and its later amendments or comparable ethical standards. The approval of the study's protocol was not required at the time of its conduct as per applicable institutional and national rules or guidelines. All participants were informed in written form about the consequences of and rights during and after their participation in this study. Participants' consent was implied through completion of the survey. The study's protocol involved no deception at all.

\subsection{Procedure}

In each session of the experiment, between three and 12 participants ${ }^{2}$ were welcomed in the laboratory, randomly seated (covered by individual privacy screens), and informed that they would anonymously interact in randomly chosen groups of three persons throughout the entire experiment. The number of subjects participating in one session influenced neither voting, $\chi^{2}(9,272)=8.63, p=0.47$, nor cooperative behavior $(F(9,272)=0.94, p=0.49)$.

In phase 1 , we employed a welfare-state game to exogenously induce inequality (Biniossek and Fetchenhauer 2007; Lotz and Fetchenhauer 2012; Schlösser et al. 2018). Each group of three represented a fictive society as each participant was randomly assigned to either the role of an upper-class, middle-class, or lower-class member (labeled as Person A, B, or C, respectively). After learning about their respective positions in the simulated society, subjects had to determine the level of inequality by democratically voting for one of two alternative distributional systems within their society. Thereby, alternative 1 provided a relatively equal income distribution (Person $A=€ 5$; Person $B=€ 4$; Person $C=€ 3$ ), whereas alternative 2 provided a relatively unequal income distribution (Person $A=€ 10$; Person $B=€ 6$; Person $\mathrm{C}=€ 1$ ) yet higher societal wealth in total. With a Gini coefficient of 0.273 , alternative 1 was comparable to the Nordic countries (e.g., Gini coefficient for Finland in 2012: 0.278), while alternative 2 (Gini coefficient=0.427) was comparable to the United States (Gini coefficient in 2013=0.411; World Bank 2015). We implemented a higher total wealth in the unequal society ( $€ 17$ vs. $€ 12$ ) to increase the ecological validity, as it has been asserted by economic theorists that a more equal wealth distribution in the real world usually comes with the costs of the redistributing institutions, such as tax collecting, administration, etc. (see, for example, Baldassarri and Piga 1996; Browning and Johnson 1984; Ballard 1988; Browning 1993). This overall wealth difference between the two alternatives is comparable to the difference in gross domestic product (GDP per capita between Finland and the United States, as the two differ by approximately 40\% (OECD 2015; World Bank 2015). The participants answered several control questions to ensure their understanding of the situation. After being informed about their actual position as Person A, B, or C, participants voted for their preferred level of inequality within their micro society by voting for either alternative 1 or 2 . An experimenter then collected the three votes anonymously. Up to the end of this first part, participants did not know about the

\footnotetext{
2 There was only one session run with three participants and 12 sessions with six participants.
} 
content of the second phase; instead, they only were informed at the beginning of phase 1 that they would receive new material to answer in a second phase.

At the beginning of phase 2, then, participants received a second questionnaire that informed them of the votes of all members of their group; the outcome of the group's majority decision, which determined the actual distributional system; and their individual payment resulting from that decision. This was followed by detailed instructions for the public-good game that we used to measure cooperative behavior, including extensive descriptions of the outcomes for all three participants for different contribution scenarios. Each participant received an endowment of $€ 3$ and had the opportunity to contribute every possible integer amount $(€ 0, € 1, € 2$, $€ 3$ ) of this to the public good.

However, any kept amount was directly added to the earnings of the respective participant, whereas the contributed amount was multiplied by 1.5 and distributed equally among all three group members. Hence, every $€ 1$ invested increased the group's total payoff by $€ 1.50$ and earned each participant $€ 0.50(=€ 1 \cdot 1.5 / 3)$.

Consequently, in the collective-good game, participants could earn up to $€ 7.50$ in the event that they did not cooperate but all others did. Moreover, they could potentially earn only $€ 1.50$ in the event that they did cooperate but all others did not. Thus, we would argue that our student participants were sufficiently incentivized to take their decision seriously.

We deliberately gave an equally high initial endowment to all participants, independent of their fictive societal class. The reasoning behind this choice was to make the cooperation situation one with increased external validity, as the cooperation task should reflect one that could potentially emerge under an analogous background in reality. The membership to a societal class usually is a very constant state in peoples' lives. Hence, asked to contribute to a public good with income-independent costs, e.g., public infrastructure measures such as street renovation, takes place under different and already acquired individual wealth. Thus, unequal starting endowments in the public-good game itself would have been a potential source of confounders. As the distribution rule of the public good aims for equal repayment, starting with different amounts would have implied an unbalanced redistribution mechanism within the public-good game in the sense that cooperation would have been cheaper for the upper class and pricey for the lower-class members. Thus, the interpretation of effects on cooperation by the implemented wealth allocation would have been much more complicated if we had used, in this sense, a biased redistribution mechanism in the public-good game.

The understanding of this procedure was checked by three control questions (one of three versions: "Person $\mathrm{A}$ contributes $€ 3$, Person $\mathrm{B} € 1$, and Person $\mathrm{C} € 0$ to the public good. For this case, Person A receives $€_{\ldots}$, Person $\mathrm{B}$ receives $€ \_$, and Person $\mathrm{C} € \ldots$ _) right before the participants made their final decision about their contribution to the public good. These control questions obviously were quite hard to answer for some of our participants, as they involve some calculations: For the above example, the answer would be the following: Because all participants together contributed $4 €$, the public good increases by a factor of 1.5 to $€ 6$. As this amount then was distributed equally between the three participants, Person A would walk home with $€ 0$ (kept) $+€ 2=€ 2$, Person B with $€ 2$ (kept) $+€ 2=€ 4$, and 
Person $\mathrm{C}$ with $€ 3$ (kept) $+€ 2=€ 5$. If one of these nine answers (three amounts within three scenarios) was answered incorrectly, the participant was excluded, as we could not assume full understanding of the public-good game's logic.

Finally, participants answered some sociodemographic questions, received their actual payoffs, and then were thanked and dismissed.

\section{Results}

First, we analyzed the results of the democratic vote. Table 1 reports the voting behavior of our participants and indicates that, as expected, a majority of $158(58 \%)$ of all participants preferred a society with a low degree of inequality to a society with a high degree of inequality ( $p=0.009$, two-sided binomial test against $50 \%$ ). Based on a theoretical prediction that assumes selfish and rational voters, the prediction would be a proportion of $33 \%$ of votes for the equal and $66 \%$ for the unequal wealth distribution; another binominal test against this predicted ratio also shows that the realized ratio of votes significantly differs $(p<0.001$, two-sided). However, members of the societal classes strongly differed in their votes $\left(\chi^{2}[2, n=272)\right]=64.57$, $p<0.001)$ : While $92 \%$ of lower-class participants voted in favor of a low degree of inequality, only $40 \%$ of upper-class and $43 \%$ of middle-class participants did so. Votes of upper-class and middle-class participants did not differ from another $\left(\chi^{2}[1\right.$, $n=182]=0.20, p=0.65)$. Hence, in accordance with the assumption that lower-class participants in particular will prefer a low degree of wealth inequality, the overall preference for low inequality is based on the votes of lower-class participants.

Table 2 reports the distribution of participants in accordance with their class affiliation and the degree of inequality resulting from the democratic vote within their micro society. Overall, $62.5 \%$ of the participants were eventually compensated as members of an equal society, and $37.5 \%$ of the participants were compensated as members of an unequal society.

Table 1 Voting of the participants separated by class affiliation

\begin{tabular}{lllll}
\hline Vote & Upper class $(\%)$ & Middle class $(\%)$ & Lower class $(\%)$ & Total $(\%)$ \\
\hline Low inequality & 40 & 43 & 92 & 58 \\
High inequality & 60 & 57 & 8 & 42 \\
\hline
\end{tabular}

Low inequality $=$ societies that eventually implemented a low degree of inequality; high inequality $=$ societies that eventually implemented a high degree of inequality. Percentages are based on 272 participants, with 91 upper-class participants, 91 middle-class participants, and 90 lower-class participants

Table 2 Numbers of participants separated by degree of inequality and class affiliation

\begin{tabular}{lllll}
\hline Society & Upper class (n) & Middle class (n) & Lower class (n) & Total \\
\hline Low inequality & 56 & 55 & 59 & 170 \\
High inequality & 35 & 36 & 31 & 102 \\
Total & 91 & 91 & 90 & 272 \\
\hline
\end{tabular}

Low inequality $=$ societies that eventually implemented a low degree of inequality; high inequality $=$ societies that eventually implemented a high degree of inequality 
Fig. 1 Public-good game contributions separated by society affiliation

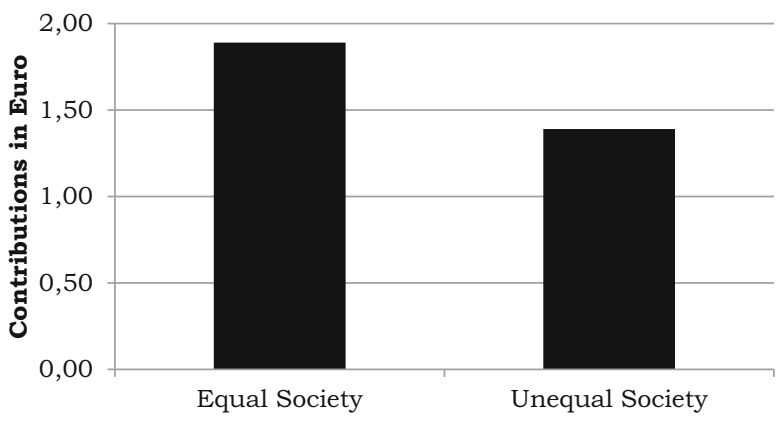

In the second step of our analysis, we wanted to answer the primary research question about whether democratically determined inequality decreases cooperation. The presented results indicate that subsequent cooperation was indeed negatively influenced by high inequality: On average, the participants contributed $€ 1.70$ $(\mathrm{SD}=1.20)$ to the public good and thus $57 \%$ of their initial endowment. Figure 1 depicts the average contributions to the public good separated by society (i.e., unequal society or equal society). In line with our prediction, the results reveal that inequality was related to lower levels of cooperation. The participants whose groups had previously chosen an equal society contributed $€ 1.89(\mathrm{SD}=1.14)$ on average, whereas the participants whose groups had previously chosen an unequal society contributed only $€ 1.39$ ( $\mathrm{SD}=1.24$; two-sided Mann-Whitney $\mathrm{U}$ test: $\mathrm{U}=6700.5$, $p<0.001)$. Therefore, these results affirm our main research hypothesis, which stated that democratically determined inequality decrease cooperative behavior.

In the third step of our analysis, we explored the potential mechanisms on which the negative association between inequality and cooperation was based. The first mechanism that we suggested was based on self-selection and argued that people with a predisposition for cooperation might self-select into a society with low inequality. Analysis of the relationship between the participants' own votes and their contributions in the public-good game revealed that results do not speak for this mechanism. Table 3 provides the results of three ordinary least squares (OLS) models that employ public-good game contributions as a dependent variable. Model 1 shows that a participant's vote had no general effect on his or her contributions to the public-good game. Therefore, the participants who voted for the equal society and those who voted for the unequal society exhibited similar levels of cooperation. Hence, cooperation in equal societies was not high because people who prefer the equal society were more cooperative in general. This result remains robust when we control for the influence of class affiliation on contributions using the upper class as the reference group (model 2). We found that neither membership in the middle class or lower class nor votes were associated with changes in cooperative behavior. In addition, by testing for a potential interaction effect of class affiliation with voting (model 3), we found no evidence supporting the hypothesis that equality-preferring individuals were more cooperative. Nevertheless, it should be noted that lower-class participants who voted for the unequal society cooperated even more than the reference group $(p=0.05)$. Their contributions to the public good exceeded those of 
Table 3 Ordinary least squares regression models for the influence of the own vote and class affiliation on public-good game contributions

\begin{tabular}{|c|c|c|c|}
\hline & $\begin{array}{l}\text { Model } 1 \\
b(\mathrm{SD})\end{array}$ & $\begin{array}{l}\text { Model } 2 \\
b(\mathrm{SD})\end{array}$ & $\begin{array}{l}\text { Model } 3 \\
b \text { (SD) }\end{array}$ \\
\hline Constant & $1.77(0.10)^{* * *}$ & $1.93(0.16)^{* * *}$ & $1.86(0.20)^{* * *}$ \\
\hline Vote inequality & $-0.15(0.15)$ & $-0.21(0.17)$ & $-0.10(0.25)$ \\
\hline Middle class & - & $-0.21(0.18)$ & $0.11(0.27)$ \\
\hline Lower class & - & $-0.21(0.20)$ & $-0.24(0.24)$ \\
\hline $\begin{array}{l}\text { Vote inequality } \mathrm{x} \\
\text { middle class }\end{array}$ & - & - & $-0.55(0.36)$ \\
\hline $\begin{array}{l}\text { Vote inequality } \mathrm{x} \\
\text { lower class }\end{array}$ & - & - & $1.04(0.53)^{*}$ \\
\hline$R^{2}$ & 0.004 & 0.01 & $0.04 *$ \\
\hline$\Delta R^{2}$ & 0.004 & 0.006 & $0.03^{* *}$ \\
\hline
\end{tabular}

"Vote inequality" is a dummy variable with a value of 1 representing a vote for a high degree of inequality. "Middle class" and "lower class" are dummy variables coded in a way that a value of 1 represents the respective feature, whereas upper class is the reference

$S D$ standard deviation

$* * * p<0.001, * * p<0.01, * p<0.05$

upper-class participants who voted for the equality system by, on average, $€ 1.04$. At first glance, this behavior might be perceived as counterintuitive; however, one might simply regard this group as being social-output maximizers. With their initial vote for an unequal society, they do not seek personal profit but aim to increase total societal wealth, and they consistently contribute high amounts to the public good to increase the total societal wealth irrespective of their individual outcomes.

However, we found no evidence suggesting that cooperative individuals show a general preference for equal income distributions, as those participants who initially voted for an equal society did not exhibit more cooperative behavior than their counterparts. Consequently, our results contradict the notion that a mechanism based on self-selection underlies the negative association between inequality and cooperation. Please note that these results do not change when rank-based regression analysis was used.

The second mechanism that we suggested was based on similarity considerations and argued that inequality does not necessarily decrease cooperation; instead, dissimilar attitudes toward the desirable degree of inequality would be responsible for a decrease in cooperation. However, we found no evidence to support the notion that such a mechanism based on similarity considerations underlies the association between inequality and cooperation: Model 4 in Table 4 shows that attitudinal similarity, measured by the conformity of the participants' votes and the implemented degree of inequality in their society, did not affect the participants' behaviors in the public-good game. ${ }^{3}$ Hence, dissimilar attitudes toward the desirable degree of inequality did not decrease cooperation in our experiment.

\footnotetext{
3 Similar results were obtained by analyzing a trichotomous variable with -1 indicating that the other group members voted for the opposite alternative, 0 indicating that one group member voted for the same alternative and the other one for the opposite alternative, and 1 indicating that the other group members voted for the same alternative as the participant.
} 
Table 4 Ordinary least squares regression models for the influence of attitudinal similarity and class affiliation on public-good game contributions

\begin{tabular}{llll}
\hline & $\begin{array}{l}\text { Model } 4 \\
b(\mathrm{SD})\end{array}$ & $\begin{array}{l}\text { Model } 5 \\
b(\mathrm{SD})\end{array}$ & $\begin{array}{l}\text { Model 6 } \\
b(\mathrm{SD})\end{array}$ \\
\hline Constant & $1.47(0.14)^{* * *}$ & $1.56(0.17)^{* * *}$ & $1.63(0.24)^{* * *}$ \\
Attitudinal similarity & $0.31(0.16)$ & $0.33(0.17)^{*}$ & $0.24(0.28)$ \\
Middle class & - & $-0.22(0.18)$ & $-0.01(0.37)$ \\
Lower class & - & $-0.08(0.18)$ & $-0.36(0.33)$ \\
Attitudinal similarity x & - & - & $-0.25(0.42)$ \\
middle class & & & \\
Attitudinal similarity x & - & - & $0.41(0.39)$ \\
lower class & & & \\
$R^{2}$ & 0.01 & 0.02 & 0.03 \\
$\Delta R^{2}$ & 0.01 & 0.01 & 0.01 \\
\hline
\end{tabular}

Attitudinal similarity, middle class, and lower class are dummy variables coded in a way that a value of 1 represents the respective feature

$S D$ standard deviation

$* * * p<0.001, * * p<0.01, * p<0.05$

This finding remains robust under control of the influence of class affiliation (model 5) and, additionally, the interactions between class affiliation and attitudinal similarity (model 6). ${ }^{4}$ Thus, we found no evidence supporting the notion that attitudinal similarity alters cooperative behavior, which clearly contradicts the predictions of a mechanism based on similarity consideration.

The third mechanism that we suggested was based on risk considerations and argued that the democratic implementation of inequality decreases cooperation because it increases the perceived risk of exploitation. This mechanism would predict that, due to the perception of such higher risk, all members of a society should reduce cooperation. Hence, we investigated how class affiliation and inequality interacted with regard to cooperation. Table 5 shows the results of this analysis. While regression model 7 replicates the previously stated main finding that high inequality reduced cooperation, model 8 indicates that this finding does not change under the control for the respective class affiliation of our participants. However, the reported results of model 9 do not support the predictions of the risk-based mechanism: First, within the equal societies, cooperation was stable between classes, as indicated by the insignificant coefficients representing the effect of membership in the middle and the lower classes. Second, the significant effect of being affiliated with an unequal society reported in models 7 and 8 vanishes in model 9, which indicates that contributions to the public good did not differ between upper-class participants affiliated with the equal society and the unequal society. Therefore, inequality did not reduce cooperation among all members of an unequal society, which contradicts the assumptions made regarding a mechanism based on risk considerations.

The fourth suggested mechanism is based on inequality aversion and argued that reduced cooperation under conditions of high inequality is a by-product of attempt-

\footnotetext{
4 The explanative power of model 5 remains insignificant $(F[3,268]=1.74, p=0.16)$ against a 0 -model, indicating that the seemingly significant effect of attitudinal similarity should not be interpreted as such.
} 
Table 5 Ordinary least squares regression models for the influence of society and class affiliation on public-good game contributions

\begin{tabular}{llll}
\hline & $\begin{array}{l}\text { Model } 7 \\
b(\mathrm{SD})\end{array}$ & $\begin{array}{l}\text { Model } 8 \\
b(\mathrm{SD})\end{array}$ & $\begin{array}{l}\text { Model } 9 \\
b(\mathrm{SD})\end{array}$ \\
\hline Constant & $1.89(0.09)^{* * *}$ & $1.99(0.14)^{* * *}$ & $1.79(0.16)^{* * *}$ \\
Unequal society & $-0.50(0.15)^{* *}$ & $-0.50(0.15)^{* *}$ & $0.04(0.25)$ \\
Middle class & - & $-0.19(0.18)$ & $0.14(0.22)$ \\
Lower class & - & $-0.12(0.18)$ & $0.16(0.22)$ \\
Unequal society x & - & - & $-0.86(0.36)^{*}$ \\
middle class & - & - & $-0.77(0.36)^{*}$ \\
Unequal society x & & & \\
lower class & $0.04 * * *$ & $0.05 * *$ & $0.07 * *$ \\
$R^{2}$ & $0.04 * * *$ & 0.004 & $0.03 *$ \\
$\Delta R^{2}$ & & & \\
\hline
\end{tabular}

Unequal society, middle class, and lower class are dummy variables coded in a way that 1 represents the respective feature

$S D$ standard deviation

$* * * p<0.001, * * p<0.01, * p<0.05$

ing to install a more equal distribution of wealth. For this experiment, the mechanism predicted that inequality reduces cooperation only among lower-class participants. Yet this prediction is not supported by model 9. It shows that the lower levels of cooperation in unequal societies are driven by low levels of cooperation among their middle-class and lower-class participants. Middle-class participants and lower-class participants in the unequal society contributed less in the unequal society ( $€ 0.86$ and $€ 0.77$, respectively) than the reference group of upper-class participants in the equal society. Hence, contradicting a mechanism based on inequality aversion, we found that inequality decreased cooperation not only for lower-class participants but also for middle-class participants.

Finally, the fifth mechanism that we suggested was based on motivated reasoning and assumed that inequality harms cooperation because it delivers a justification for self-serving behavior. The mechanism assumed that inequality would cause low levels of cooperation among middle-class and lower-class participants but that cooperation would not be affected in the upper class. The results of our experiment are in line with such a prediction: As illustrated in Fig. 2, the average public-good game contributions of upper-class, middle-class, and lower-class participants differ in societies with high and low inequality. As already noted, upper-class participants' contributions did not significantly differ in these two societies, which indicates similar levels of cooperation. However, middle-class and lower-class participants of the unequal society cooperated less than their respective counterparts in the equal society. Middle-class participants in the equal society contributed more willingly to the public good than their counterparts in the unequal society (two-sided Mann-Whitney $\mathrm{U}$ test: $\mathrm{U}=601, p<0.001)$, and the same is true with regard to lower-class participants (two sided Mann-Whitney $\mathrm{U}$ test: $\mathrm{U}=629.5, p=0.01$ ). Hence, differences in contributions between the equal and unequal societies seem to be caused by contribution differences between the middle-class and lower-class participants of both societies. As said, the results are in line with the predictions of a mechanism based 
Fig. 2 Public-good game contributions separated by society and class affiliation

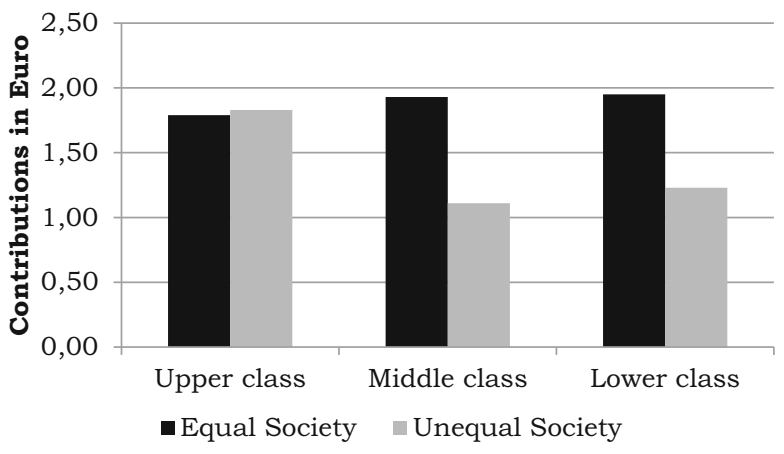

on motivated reasoning. But we are not able to provide any other (e.g., process) data to further validate that notion.

In summary, the presented findings do not support explanative mechanisms based on self-selection, similarity considerations, risk considerations, or inequality aversion, while they are in line with the notion that a mechanism based on motivated reasoning causes inequality to reduce cooperation. ${ }^{5}$

\section{Discussion}

Previous research has found that the origin of economic inequality plays a critical role in its eventual effect on cooperative behavior. With a novel experimental design, this study investigated the effect of economic inequality on cooperative behavior when inequality is the result of a democratic decision.

Regarding the democratic determination of the degree of inequality in a society, we found further evidence supporting a general inequality aversion (Bolton and Ockenfels 2000; Fehr and Schmidt 1999) and replicated the findings of former studies that utilized the experimental welfare-state game by Lotz and Fetchenhauer (2012). Most of our participants voted for a low degree of inequality. In particular, lower-class participants voted almost exclusively for a society with low inequality, but we also found notable proportions of upper-class and middle-class participants who voted for low inequality even though this in opposite to their financial selfinterest.

Furthermore, consistent with our main assumption, our results suggest that inequality resulting from these democratic decisions reduces contributions to the public good and hence cooperation. Interestingly, previous research argued that economic inequality primarily affects people if it results from an unfair procedure (Bolton et al. 2005; Haile et al. 2008). At first glance, the implementation of a policy that is supported by the majority and is determined democratically seems to be an example of a fair procedure, yet our results indicate that inequality still reduces the

\footnotetext{
5 As one approach to further test the mechanisms against each other, a regression model integrating the presented regression models 3,6 , and 9 in one new model revealed consistent results, indicating the presented finding to be robust.
} 
level of societal cooperation. Hence, future research should investigate the perceived fairness of democratic processes in the regarded context. Furthermore, conditions of procedural justice should be determined under which inequality harms cooperation, even if it results from a seemingly fair procedure.

With regard to the basic mechanism underlying the association between inequality and cooperation, we found that individuals who initially preferred a distribution based on the standards of an equal society did not show more cooperative behavior than those who voted for an unequal society. Consequently, the result of the majority vote rather than the vote itself seemed to ultimately determine the cooperation levels among our participants. Hence, a mechanism based on the self-selection of more cooperative individuals into a society with a higher degree of inequality could not explain the negative relationship between inequality and cooperation. Furthermore, the conformity of the participants' votes and thus their apparent similarity in attitudes did not alter cooperative behavior. Therefore, we also did not find that a mechanism based on similarity considerations would explain the levels of cooperation.

Thus, so far our results correspond with findings that indicate that people use levels of endogenously evoked inequality to determine the risk of cooperation, with higher inequality signaling previously selfish and thus uncooperative behavior (Greiner et al. 2012). However, if we consider our results regarding the interaction effect between the implemented level of inequality of a micro society and membership in the societal classes, an explanation based on the perceived risk of exploitation is not supported either. Within the conducted experiment, a risk-based mechanism predicts a cooperation-reducing effect of inequality with regard to all the observed societal classes. Instead, our results clearly contradict this conjecture by showing that inequality decreases cooperation only among middle-class and lowerclass participants.

In line with the latter part of the previously mentioned finding, a mechanism based on inequality aversion predicts that a high degree of inequality decreases cooperation, especially among lower-class participants. However, the finding that inequality also decreases cooperation among middle-class participants is not in line with this reasoning. Therefore, we can, to a certain degree, also rule out that inequality aversion underlies the negative effect of inequality on cooperation, at least for the middle class.

It might be argued that receiving more or less money in the first part of the study caused the differences in cooperation behavior, regardless of the voting process. However, if this assumption were to hold true, one would predict more cooperation for the unequal distribution, as this distribution comprises what Bolton and Ockenfels (2006) called a "majority gain, a minority lose." Namely, the incomes of Persons A ( $€ 5$ to $€ 10$ ) and Persons B ( $€ 4$ to $€ 6$ ) increase with more unequal wealth distribution, and only the incomes of Persons $C$ decrease ( $€ 3$ to $€ 1$ ). Nevertheless, our results show that overall cooperativeness is lower in those societies that end up more unequal compared with the less unequal (respectively, $€ 1.89$ versus $€ 1.39$ average contribution per participant). Specifically, as depicted in Fig. 2, Persons' A cooperativeness does not increase for the unequal case, even given their large increase in income (doubled from $€ 5$ to $€ 10$ ) but is indistinguishable between the two conditions ( mean $=1.79$ vs. mean $=1.83$ ); Persons' B cooperativeness 
even decreased in the unequal case ( $€ 1.11$ vs. $€ 1.93$ ) instead of increasing, given that their income increased (from $€ 4$ to $€ 6$ ). Taken together, these results show that it seems implausible that sheer income effects are able to explain actual levels of cooperation, as we observed contradictory evidence for two of three groups (Persons A and B). Hence, other motives must be more relevant for cooperative behavior than the consideration that cooperation is relatively cheaper for those with more income.

From all the proposed potential mechanisms, our results support a mechanism based on motivated reasoning the most. This mechanism correctly predicted that inequality negatively affects cooperation in general because it causes less cooperation among middle-class and lower-class participants. Hence, it seems as if inequality harms cooperation in democratic systems because it delivers middle-class and lowerclass participants a sufficiently plausible justification for self-serving, uncooperative behavior. The finding that cooperative behavior of the upper-class members did not depend on the implemented degree of inequality was compatible with the prediction based on findings that show blindness for inequality, justification of the prevailing economic system, and the holding of beliefs that oppose wealth redistribution of subjectively upper-class members (Rodriguez-Bailon et al. 2017). However, such an insignificant finding might show up simply due to insufficient statistical power. Nevertheless, we are confident that the very small difference in subsequent cooperation between the upper-class members in our equal and unequal societies might reach significance only under uncommon conditions of extreme statistical power. Most importantly, future research should investigate whether the proposed mechanisms underlying the decisions of upper-class, middle-class, and lower-class participants resemble reality by implementing appropriate mediator variables to examine cognitive processes.

Furthermore, it would be worthwhile to explore the impact of democratically determined inequality on cooperative behavior if participants repeatedly interact with one another. If our assumptions about the reasoning underlying the observed behavioral pattern are correct, upper-class participants, for example, would be expected to adjust their behavior in future interactions. As outlined above, upper-class participants might initially be motivated to believe that the implementation of inequality and contributions to the public good operate independently. However, they may abandon this belief once they realize that the two situations are not perceived to be independent by other members of the society. Consequently, they might be motivated to reason in favor of not cooperating in the future. Upper-class participants might even perceive themselves as falling prey to unjustified exploitation by middle-class and lower-class participants and thus ultimately reduce their level of cooperation. Hence, future research should explore the role of motivated reasoning in the context of inequality in general and with regard to the association between inequality and cooperation in particular.

Experimental laboratory studies, of course, do not come without limitations: Usually the increase in internal validity by measuring behavior within an extremely "distilled" version of a real situation (e.g., voting decision and subsequent cooperation) comes with a decrease in external validity. This fundamental problem naturally also applies to the experimental study presented here. With respect to external validity, 
two concerns regarding the sample of participants are commonly criticized: its lack of representativeness and, at the same time, the heterogeneity in specific motives for actual behavior shown by, usually, students in the laboratory context (for an indepth discussion of not only these issues, see Lenger and Wolf 2018; Bader 2018 and Diekmann 2018). Regarding potential self-selection effects that stem from an established and managed participant pool, in the sense that these participants are even not representative of the student population, we would like to argue that this critique does not apply to our sample. Participants were approached on campus and asked to take part in a study, and an appointment for the actual participation in the laboratory about one week later was fixed right at the spot. Thus, our participants did not stem from a pool of "semiprofessional" study gatherers (in line with Berger 2015). Furthermore, participating students came from a large variety of about 45 different majors of studies.

Furthermore, it can be assumed that actual behavior and its respective motives show even a larger variety in more representative samples. Of course, it can also be assumed that the average behavioral effects of randomly ending up in a specific societal position, before voting for one of two wealth allocations, on subsequent cooperativeness shows a pattern that is based on heterogeneous and mixed motives. In the real world, this would also be the case. What we cannot answer is the question of whether a majority of these motives would be the same between our student sample and a representative sample. We are quite confident that in the real world two potential major groups of motives would also be relevant for voting decision and subsequent cooperation: motives guided by self-interest and, in contrast to these, motives guided by justice considerations and cooperativeness. We did not observe an extreme proneness of our sample members to vote for equality and show cooperative behavior-as one would assume if self-selection effects had brought only the most cooperative students in our laboratory. Nevertheless, we do not doubt that the levels of voting for a more equal wealth allocation and cooperativeness would differ if the sample had been a representative one. But, given that the relevance of two broad groups of motives (self-interest-guided vs. justice concerns) can be assumed for a student and a representative sample alike, we anticipated an analogue pattern of the directions of effects for the latter, as long as the relative weighting of these motives did not differ too much (in line with Bader 2018). To specify the generalizability of our findings, it would be, of course, necessary to conduct the respective field study with more representative or more specific samples. For instance, Henrich et al. (2005) did this by conducting (not only) public-good games in 15 small-scale societies and consistently found that a model based on the self-interested homo economicus fails to describe actual behavior and to that respect is consistent with what has been found with student samples in laboratories of western universities (e.g., Ostrom and Walker 2003). Finally, note that representativeness is not a necessary condition for testing causal hypotheses against each other (see also Diekmann 2018).

In summary, our results indicate that economic inequality resulting from a democratic voting process reduces subsequent cooperative behavior in societies by particularly affecting the cooperativeness of middle-class and lower-class members. The basic mechanism behind this association is based neither on self-selection, similarity considerations, risk considerations, nor inequality aversion; instead, the results fit 
an assumed mechanism that is based on motivated reasoning. Thus, the negative effect of inequality on cooperation goes beyond what might be explained by stable preferences for cooperation, which implies that reducing economic inequality in a society potentially elevates the level of societal cooperation, thereby strengthening societal prosperity. Strikingly, implementing a strongly unequal wealth distribution by a procedure that is usually considered fair, namely a democratic majority vote, does not hinder its negative effect on cooperation.

Author Contribution Study conceptualization: all authors; data collection: Tim Steiniger; data preparation: Thomas Schlösser, Tim Steiniger; data analysis: Thomas Schlösser, Tim Steiniger; report writing: all authors.

Funding Open Access funding provided by Projekt DEAL.

Open Access This article is licensed under a Creative Commons Attribution 4.0 International License, which permits use, sharing, adaptation, distribution and reproduction in any medium or format, as long as you give appropriate credit to the original author(s) and the source, provide a link to the Creative Commons licence, and indicate if changes were made. The images or other third party material in this article are included in the article's Creative Commons licence, unless indicated otherwise in a credit line to the material. If material is not included in the article's Creative Commons licence and your intended use is not permitted by statutory regulation or exceeds the permitted use, you will need to obtain permission directly from the copyright holder. To view a copy of this licence, visit http://creativecommons.org/licenses/by/4. 0 .

\section{References}

Anderson, Lisa R., Jennifer M. Mellor and Jeffrey Milyo. 2006. Induced heterogeneity in trust experiments. Experimental Economics 9:223-235.

Anderson, Lisa R., Jennifer M. Mellor and Jeffrey Milyo. 2008. Inequality and public good provision: an experimental analysis. The Journal of Socio-Economics 37:1010-1028.

Bader, Felix. 2018. Motivationsheterogenität in Laborexperimenten mit Studierenden. Problemspezifizierung und Auswege. Soziale Welt 69:101-107.

Balafoutas, Loukas, Martin G. Kocher, Louis Putterman and Matthias Sutter. 2013. Equality, equity and incentives: An experiment. European Economic Review 60:32-51.

Baldassarri, Mario and Gustavo Piga. 1996. Distributive equity and economic efficiency: Trade-off and synergy. In Equity, efficiency and growth: The future of the welfare state, eds. M. Baldassarri, L. Paganetto and E. S. Phelps, pp. 257-275. Basingstoke: Macmillan

Ballard, Charles L. 1988. The marginal efficiency cost of redistribution. The American Economic Review 78:1019-1033.

Berger, Roger. 2015. Das Laborexperiment als sozialer Prozess. Soziale Welt, Sonderband 22:53-76.

Bergh, Andreas, and Christian Bjørnskov. 2014. Trust, welfare states and income equality: sorting out the causality. European Journal of Political Economy 35:183-199.

Biniossek, Claudia, and Detlef Fetchenhauer. 2007. Fairness als Kollektivgut [Fairness as a collective good]. Wirtschaftspsychologie 9:68-82.

Bolton, Gary E., and Axel Ockenfels. 2000. A theory of equity, reciprocity, and competition. American Economic Review 90:166-193.

Bolton, Gary E., and Axel Ockenfels. 2006. Inequality aversion, efficiency, and maximin preferences in simple distribution experiments: Comment. American Economic Review 96:1906-1911.

Bolton, Gary E., Jordi Brandts and Axel Ockenfels. 2005. Fair procedures: evidence from games involving lotteries. The Economic Journal 115:1054-1076.

Browning, Edgar K. 1993. The marginal cost of redistribution. Public Finance Quarterly 21:3-32.

Browning, Edgar K., and William R. Johnson. 1984. The trade-off between equality and efficiency. Journal of Political Economy 92:175-203.

Buckley, Edward, and Rachel Croson. 2006. Income and wealth heterogeneity in the voluntary provision of linear public goods. Journal of Public Economics 90:935-995.

Dal Bó, Pedro, Andrew Foster and Louis Putterman. 2010. Institutions and behavior: Experimental evidence on the effects of democracy. American Economic Review 100:2205-2229. 
Caplin, Andrew, and John Leahy. 2001. Psychological expected utility theory and anticipatory feelings. Quarterly Journal of Economics 116:55-81.

Chan, Kenneth S., Stuart Mestelman, Rob Moir and R. Andrew Muller. 1996. The voluntary provision of public goods under varying income distributions. The Canadian Journal of Economics 29:54-59.

Chan, Kenneth S., Stuart Mestelman, Rob Moir and R. Andrew Muller. 1999. Heterogeneity and the voluntary provision of public goods. Experimental Economics 2:5-30.

Dawes, Christopher T., James H. Fowler, Tim Johnson, Richard McElreath and Oleg Smirnov. 2007. Egalitarian motives in humans. Nature 446:794-796.

Diekmann, Andreas. 2018. Experimentelle Studien und Repräsentativität. Zur Klärung einiger Irrtümer und Missverständnisse. Soziale Welt 69:95-100.

van Dijk, Frans, Joep Sonnemans and Frans van Winden. 2002. Social ties in a public good experiment. Journal of Public Economics 85:275-299.

Fehr, Ernst, and Klaus M. Schmidt. 1999. A theory of fairness, competition, and cooperation. Quarterly Journal of Economics 114:817-868.

Fischer, Ilan. 2009. Friend or foe: Subjective expected relative similarity as a determinant of cooperation. Journal of Experimental Psychology: General 138:341-350.

Greiner, Ben, Axel Ockenfels and Peter Werner. 2012. The dynamic interplay of inequality and trust- an experimental study. Journal of Economic Behavior \& Organization 81:355-365.

Haile, Daniel, Abdolkarim Sadrieh and Harrie A. A. Verbon. 2008. Self-serving dictators and economic growth. Journal of Economic Behavior \& Organization 67:573-586.

Henrich, Joseph, Robert Boyd, Samuel Bowles and Colin Camerer. 2005. 'Economic Man' in Cross-Cultural Perspective: Behavioral Experiments in 15 Small-Scale Societies. Behavioral and Brain Sciences 28:795-815.

Isaac, R. Mark, and James Walker. 1988. Communication and free-riding behaviour: the voluntary contribution mechanism. Economic Inquiry 26:585-608.

Kahneman, Daniel, and Amos Tversky. 1979. Prospect theory: an analysis of decision under risk. Econometrica 47:263-291.

Knack, Stephan, and Philip Keefer. 1997. Does social capital have an economic payoff? A cross-country investigation. The Quarterly Journal of Economics 112:1251-1288.

Kosfeld, Michael, Akira Okada and Arno Riedel. 2009. Institution formation in public good games. American Economic Review 99:1335-1355.

Kunda, Ziva. 1990. The case of motivated reasoning. Psychological Bulletin 108:480-498.

Lenger, Alexander, and Stephan Wolf, 2018. Experimente in der Soziologie? Über die systematische Verzerrung von Experimentergebnissen aufgrund strategisch agierender studentischer Teilnehmertypen. Soziale Welt 69:64-94.

Lotz, Sebastian, and Detlef Fetchenhauer. 2012. Lifting the veil of ignorance in distributive justice-evidence from a welfare state game. Wirtschaftspsychologie 14:74-80.

Neumann, John von, and Oskar Morgenstern. 1944. The theory of games and economic behavior. Princeton. New York: Princeton University Press.

Norton, Michael I., and Dan Ariely. 2011. Building a better America-One wealth quintile at a time. Perspectives on Psychological Science 6:9-12.

OECD. 2015. Level of GDP per capita and productivity [Data set]. Retrieved from https://stats.oecd.org/ Index.aspx?DataSetCode=PDB_LV.

Ostrom, Elenor, and James Walker. 2003. Trust and reciprocity: Interdisciplinary lessons from experimental research. Russell Sage Foundation.

Paetzel, Fabian, and Stefan Traub. 2017. Skewness-adjusted social preferences: Experimental evidence on the relation between inequality, elite behavior, and economic efficiency. Journal of Behavioral and Experimental Economics 68:130-139.

Pruitt, Dean G., and Melvin J. Kimmel. 1977. Twenty years of experimental gaming: Critique, synthesis, and suggestions for the future. Annual Review of Psychology 28(1):363-392.

Putterman, Louis, Jean-Robert Tryan and Kenju Kamei. 2011. Public goods and voting on formal sanction schemes. Journal of Public Economics 95:1213-1222.

Rawls, John. 1971. A theory of justice. Cambridge, MA: Harvard University Press.

Reuben, Ernesto, and Arno Riedl. 2013. Enforcement of contribution norms in public good games with heterogeneous populations. Games and Economic Behavior 77:122-137.

Riolo, Rick L., Michael D. Cohen and Robert Axelrod. 2001. Evolution of cooperation without reciprocity. Nature 414:441-443. 
Rodriguez-Bailon, Rosa, Boyka Bratanova, Guillermo B. Willis, Lucia Lopez-Rodriguez, Ashley Sturrock and Steve Loughnan. 2017. Social class and ideologies of inequality: How they uphold unequal societies. Journal of Social Issues 73:99-116.

Sadrieh, Abdolkarim, and Harrie A. A. Verbon. 2006. Inequality, trust and growth. European Economic Review 50:1197-1222.

Saunders, Peter. 2010. Beware of false prophets. London: Policy Exchange.

Savage, Leonard J. 1954. The foundations of statistics. $2^{\text {nd }} \mathrm{ed.}$ 1972. Dover: Wiley

Schlösser, Thomas, Tim Steiniger, Detlef Fetchenhauer and Daniel Ehlebracht. 2018. How justice sensitivity predicts equality preferences in simulated democratic systems. Journal of Research in Personality 73C:75-81.

Sutter, Matthias, Stefan Haigner and Martin G. Kocher. 2010. Choosing the carrot or the stick? Endogenous institutional choice in social dilemma situations. Review of Economic Studies 77:1540-1566.

Walker, James M., Roy Gardner, Andrew Herr and Elinor Ostrom. 2000. Collective choice in the commons: Experimental results on proposed allocation rules and votes. The Economic Journal 110:212-234.

Wilkinson, Richard G., and Kate E. Pickett. 2009. Income inequality and social dysfunction. The Annual Review of Sociology 35:439-511.

World Bank. 2015. Gini index (World Bank estimate) [Data set]. Retrieved from http://data.worldbank.org/ indicator/SI.POV.GINI.

Zak, Paul J., and Stephen Knack. 2001. Trust and growth. The Economic Journal 111:295-321.

Thomas Schlösser 1976, Dr. rer. pol., Privatdozent am Institut für Soziologie und Sozialpsychologie (ISS) der Universität zu Köln. Forschungsgebiete: Individuelle Unterschiede in der Wahrnehmung von und Reaktion auf Ungerechtigkeit, soziale Kontexte als Determinanten normativer Rahmung, Erklärung der Grundlagen und Mechanismen von Vertrauen. Veröffentlichungen: Soziale Gerechtigkeit - Was unsere Gesellschaft aus den Erkenntnissen der Gerechtigkeitspsychologie lernen kann. Göttingen 2013 (mit M. Gollwitzer, S. Berger und B. Streicher); Justice sensitivity and cooperation dynamics in repeated public good games, Social Justice Research 31, 2018 (mit S. Berger und D. Fetchenhauer); Why People Trust: Solved Puzzles and Open Mysteries, Current Directions in Psychological Science 28(4), 2019 (mit D. Dunning und D. Fetchenhauer).

Tim Steiniger 1985, Dr. rer. pol., promovierte 2015 am Lehrstuhl für Wirtschafts- und Sozialpsychologie an der Universität zu Köln und arbeitet seit 2017 im Bereich Customer Experience eines großen deutschen Kabelnetzbetreibers. Forschungsgebiete: Ungerechtigkeitswahrnehmung und Ungerechtigkeitssensibilität. Veröffentlichungen: How justice sensitivity predicts equality preferences in simulated democratic systems, Journal of Research in Personality 73C, 2018 (mit T. Schlösser, D. Fetchenhauer und D. Ehlebracht); It's a shame, but I'm not to blame: Perceived justice and emotions in (un)equal compensation systems, Wirtschaftspsychologie 4, 2015 (mit D. Fetchenhauer und T. Schlösser).

Daniel Ehlebracht 1985, Dr. rer. pol., akademischer Rat a. Z. am Institut für Soziologie und Sozialpsychologie (ISS) der Universität zu Köln. Forschungsgebiete: Vertrauen und Zynismus, sozialer Optimismus \& Pessimismus, evolutionäre Psychologie. Veröffentlichungen: The cynical genius illusion: Exploring and debunking lay beliefs about cynicism and competence. Personality and Social Psychology Bulletin, 45(2), 2019 (mit O. Stavrova). Cynical Beliefs About Human Nature and Income: Longitudinal and Cross-Cultural Analyses, Journal of Personality and Social Psychology 110, 2016 (mit O. Stavrova); Trust at Zero Acquaintance: More a Matter of Respect Than Expectation of Reward, Journal of Personality and Social Psychology 107, 2014 (mit D. Dunning, J. Anderson, T. Schlösser and Detlef Fetchenhauer).

Detlef Fetchenhauer 1965, Prof. Dr., Inhaber des Lehrstuhls für Wirtschafts- und Sozialpsychologie am Institut für Soziologie und Sozialpsychologie (ISS) der Universität zu Köln. Forschungsgebiete: Vertrauen, Determinanten prosozialen und antisozialen Verhaltens, Ökonomische Laientheorien, Evolutionspsychologie. Veröffentlichungen: Psychologie (2. Auflage) (2017). Berlin: Springer. 